\title{
Technetium Tc 99m-labeled Rhenium Sulfide Nanocolloid
}

National Cancer Institute

\section{Source}

National Cancer Institute. Technetium Tc 99m-labeled Rhenium Sulfide Nanocolloid. NCI

Thesaurus. Code C124799.

A colloid formulation of rhenium sulfide that is labeled with the gamma-emitting epitope technetium Tc 99m (T c-99m) with diagnostic imaging activity. Upon administration, the 99mT c-colloidal rhenium sulfide is taken up by the lymph nodes. This allows imaging of the lymphatic drainage pattern during lymphoscintigraphic or sentinel lymph node mapping procedures. 